\title{
26357 - ISOCAPNIC HYPERPNOEA AND RECOVERY TIME AFTER ANESTHESIA WITH SEVOFLURANE
}

\section{Rita Katznelson MD, Leonid Minkovich, MD; Scott Beattie, MD, PhD; Ludwik Fedorko, Joseph Fisher, MD; Toronto General Hospital, UHN, Toronto, ONTARIO, Canada}

INTRODUCTION: Hyperventilation accelerates the elimination of inhaled anesthetics, but reduces arterial pCO2. Hypocapnia results in apnea and a decrease in cerebral blood flow which delays washout of anesthetic from the central nervous system and slows recovery. Isocapnic Hyperpnoea $(\mathrm{IH})$ is a method allowing increasing alveolar ventilation with maintenance of isocapnia. We compared emergence from anesthesia with sevoflurane in patients who were treated with $\mathrm{IH}$ (IH group) with those who were wakening up with assisted spontaneous ventilation (Control group).

METHODS: After REB approval we studied 14 ASA I-II patients undergoing elective gynecological surgery. No premedication was used. All patients were monitored with standard anesthesia monitoring and Bispectral EEG analysis (BIS, Aspect Medical Systems, Newton, MA, USA).

Both groups received a standardized anesthetic, which included induction with Propofol, Fentanyl, Rocuronium and endotracheal intubation. Maintenance of anesthesia was with Sevoflurane in air/oxygen mixture with fresh gas flow $1 \mathrm{~L} / \mathrm{min}$, and Fentanyl and Rocuronium as clinically indicated. At the end of the surgery patients were randomized into isocapnic hyperpnoea ( $\mathrm{IH})$, and control recovery groups. IH group patients received 2-3 times their intra-operative minute ventilation with a non-rebreathing system while maintaining isocapnia. Control patients recovered from anesthesia in the routine way. We recorded time intervals from turning off Sevoflurane to a) resumption of spontaneous ventilation, $b$ ) return of BIS value to $>75 \%, c$ ) opening of eyes to command, $d$ ) extubation, e) leaving the operating room (OR) and f) eligibility for PACU discharge. RESULTS: Eight patients were randomized to the IH group and 6 to the control group. There was no difference in age and BMI between the groups ( $50 \pm 11$ vs $47 \pm 6$ years, $\mathrm{p}=0.7 ; 26.8 \pm 6.5$ vs $28.8 \pm 8 \mathrm{~kg} / \mathrm{m}^{2}, \mathrm{p}=0.6$ )

The time for opening eyes, appropriate response to verbal command, return of BIS value $>75 \%$, extubation, leaving OR and eligibility for PACU discharge were significantly shorter for IH group (Table 1).

DISCUSSION: The results of this pilot study indicate that IH shortens Sevoflurane recovery time. 
Table 1. Comparison of duration of awakening after Sevoflurane anesthesia between the Isocapnic Hyperpnoea (IH) and Control groups.

\begin{tabular}{|l|c|c|c|}
\hline & $\begin{array}{c}\text { IH group } \\
(\mathrm{n}=8)\end{array}$ & $\begin{array}{c}\text { Control group } \\
(\mathrm{n}=6)\end{array}$ & P value \\
\hline $\begin{array}{l}\text { Resumption of spontaneous } \\
\text { ventilatica (min) }\end{array}$ & $4.4 \pm 1.9$ & $4.3 \pm 3.2$ & 0.9 \\
\hline BIS vahue $\geq 75 \%$ (min) & $4.0 \pm 1.0$ & $6.8 \pm 3.1$ & 0.05 \\
\hline $\begin{array}{l}\text { Opening eyes in response to } \\
\text { vertal comunand (min) }\end{array}$ & $6 \pm 1.6$ & $13.5 \pm 6.4$ & 0.01 \\
\hline Time of extubetion (min) & $7.1 \pm 2.4$ & $11.0 \pm 5.0$ & 0.1 \\
\hline $\begin{array}{l}\text { Fulfill criteria for leaving } \\
\text { OR (min) }\end{array}$ & $8.6 \pm 2.3$ & $14.0 \pm 5.5$ & 0.05 \\
\hline PACU discharge (min) & $52 \pm 13.6$ & $88.0 \pm 27.1$ & 0.05 \\
\hline
\end{tabular}

